\title{
Awareness Level of Family Planning Practices in School Going Adolescent Girls of Different Socio-economic Groups in Rural Sectors, West Bengal
}

\author{
Madhumita Guria, Debasis De, Tushar Kanti Bera and Debidas Ghosh* \\ Department of Bio-Medical Laboratory Science \& Management (UGC Innovative Programme \\ Funded Department), Vidyasagar University, Midnapore 721 102, West Bengal, India
}

KEYWORDS Adolescent Girls. Socio-Economic Group. Family Planning. Awareness Level. Population Explosion

\begin{abstract}
The study focuses the awareness level of different techniques adopted for family planning among the adolescent girls having the age group of $15 \mathrm{yrs}-19 \mathrm{yrs}$ (Class IX-XII standards). A cross sectional work following a pre tested semi structured questionnaire was applied on 3140 girls in total having 1140 of middle-high socio-economic group sectors and 2000 of low-socio- economic group from peri-urban or rural sectors .The girls at IX-XII standards were selected randomly from arts and commerce field only. Results revealed that the awareness level of different methods of family planning is significantly high in upper-middle socio-economic group than low-socio-economic group. The attitude of adolescent girls about the threatening side of high population is not significantly low in lowsocio-economic group but girls of high-socio-economic group are conscious about the effect of such high population on our future generation. It may be concluded that socio-economic factor plays a vital role for awareness building on the family planning methods.
\end{abstract}

\section{INTRODUCTION}

Family planning is the practices of the couple so that they prevents unwanted births and control the spacing between child birth that help to create a small and planned family. It is the best way to control the rapidly and massively growing population. So family planning contributes effectively in order to promote the health and welfare of the family group and thus contribute effectively the social development of a country. Mother's health not only affected by nutrition status but also by early marriage, frequent pregnancies, early motherhood, abortion etc. Moreover child's health is also affected by mother's health. In that contest family planning provided all the advices and methods to avoid above events. WHO (1970) has started the wider dimension of family planning starting from proper spacing and limitation of births to sex education, genetic counseling, teaching home economics and nutrition. This programme makes a planned and scientific approach to the issues and problems of

*Address for all correspondence:

Dr. Debidas Ghosh, Reader \& Head

Department of Bio-Medical Laboratory Science \&

Management, Vidyasagar University,

Midnapore 721102, West Bengal. India

E-mail: debidas_ghosh@yahoo.co.in family life and attempts to solve them to make the family life happiest, harmonious and fruitful.

Today existence of mankind is threatened by the sheer force of its numbers. The large population handicapped the socio-economic progress of the country. It results increasing unemployment, shortage of housing, pressure of land, inadequate education and health facility and shortage of every kind of human resources have made the population problem a daily experience for the people of India. Though various steps have been adopted by National Government to introduce population control measure but the report of Varma and Achhpal (1980) noted that the large peri-urban and rural sector lies unreached and still impregnable.

The measures used for birth control by preventing pregnancy after intercourse are named as contraceptive methods. There are so many contraceptive methods like physical barrier, spermicidal jelly, hormonal pill, intrauterine devices, male contraceptive, emergency contraceptives etc. The success of any method depends on the regular use, proper knowledge and to create a scientific attitude to use such method. Though the knowledge attitude and practices (KAP) about family planning is high in educated family but it is not so in low-economic family as per report of Gupta and Sinha (2006). 


\section{Review of Literature}

Saipre (1996) reported that one fifth of the world population is between 10-19 years old covering over a billion young people, $85 \%$ of which live in developing countries. Though importance of health education and health counseling for adolescents have been appreciated through formal education system like introduction of "Life Style" in school education system but there are no large scale community based studies to assess awareness levels of adolescent girl of school going children about the method of family planning programme. In India problems are more difficult and complicated because of marked socio-economic diversity as mentioned by Gupta and Sinha (2006). Shah et al. (2008) reported that socio-economic is one of the criteria of determinants of family planning. The present study was undertaken to evaluate the effect of socio-economic factor on awareness level covering the methods of family planning as well as their idea for the long term effect of such high population growth on our next generation i.e. today's adolescent girls who become the mothers of tomorrow. Diaz and Diaz (1993) showed that if quality of family planning service improved, the utilization of services and the provider enhanced.

Previous workers reported the association between literacy level and attitude adoption of family planning was to be significant in a number of studies made by Balakrishna (1971), Hate (1970) and Singh (1976). The present study was calculated here to find out the awareness about the family planning practices between school adolescent girls belong to different socioeconomic groups at rural sectors. Adolescent girls were selected here, as these girls become mother in the later life.

\section{MATERIALS AND METHOD}

The study was conducted on 3140 school going adolescent girls of 15 years to 19 years age group in 6 different blocks of Purba Medinipur and Paschim Medinipur districts of West Bengal, India. The survey programme was conducted during a period of July-2004 to May -2006.

A questionnaire was prepared in local language having questions mainly on following topics.

(a) Education level of father and mother.

(b) Economic level of family.

(c) Name of the methods adopted in family planning programme like, withdrawal technique, safe and danger period of menstrual cycle, condom, tubectomy, vasectomy, hormonal pills, emergency contraceptives

(d) Source of information about those methods. Attitude of adolescent girls towards population problems was monitored. For these purposes following questions were studied.

(a) Whether our nation is facing a serious problem of over population?

(b) Whether it should be reduced without delay?

(c) Whether increased population will may cause any problem to the happiness of the people in the country?

(d) Is there any responsibility of your to solve this problem?

(e) Whether unemployment, space problem etc. due to lack of population control. In this connection we have focused the Family Planning and Birth Control Attitude Scale (FPBCAS) described by Rajamanickam (1998).

The respondents were selected randomly from the above two socio-economic group. The questionnaire was first explained to the school girls and then they were asked to fill it carefully. The survey technique was applied on 3450 girls of age group of $15 \mathrm{yrs}-19$ yrs but in total 3140 responded, rest of the girl i.e. 310 did not give their response in the questionnaire sheet may be due to their lack of interest on such type of programme or they are too shy to respond, or are engaged in other event of school. To relate the awareness level of adolescent girls in this field with the socio-economic status the target population was divided into two groups.

Group A: The one thousand, one hundred and forty girls are belonging to high and upper middle socio-economic status (having monthly per capita family income more than Rs. 3000/-)

Group B: The two thousands girls are belonging to low socio-economic status (having monthly per capita family income of Rs. 1000/- to1500/-)

Attempt was made to stick to the given procedures as far as practicable. The data after being collected, tabulated systematically and percentage were calculated. The out come data were analyzed systematically by applying chisquare test.

\section{RESULTS AND DISCUSSION}

Adolescence is a period when physical growth and malnutrition are accompanied by 
mental and physiological development. The current billion strong generation of 10-19 year old will be the largest generation inhibitory to make transition from childhood to adulthood. Though reproductive health of adolescent girls have been neglected for long past, but for last 10-12 years an emphasis has been given to raise there awareness level by introduction of lifestyle in school education and this should be performed in friendly environment as per supported by Gandhi (1999). To know the awareness level about different family planning programme of adolescent girl belongs to upper-medium and low-socio economic group and their attitude to follow in their future life, the present work has been conducted. Adolescent girls become the tomorrow's mothers and the arts as well as commerce discipline of school education has no direct scope to enlighten the family planning programme in respect to science discipline. In that context the present survey work has been designed. To find out the co-relation between awareness of adolescent girls in the field of population control and the socio-economic group the survey was conducted and it has been indicated that education level of parent in upper-middle is significantly more than low-economic group (Table 1). In upper-middle group, the parent having post graduation of $26.31 \%$ but in low socioeconomic group it is only $4.25 \%$. In contrast, educational lavel below Madhyamik in uppermiddle group $11.84 \%$ but in low-economic- group i.e. $49.35 \%$ (Table 1 ).

Regarding the awareness level about the different methods of family planning programme, a significant difference was noted between upper- middle and low-socio economic group which was also supported by Beekle and McCabe (2006). We have noted that knowledge about hormone contraceptive pill in upper-middle group is significantly high than low-economic group but the idea about surgical technique and condom is high in low economic-group than high-medium economic group (Table 2).Regarding emergency contraceptive technique, the idea in upper-middle group is also high but in low-economic group, the rate is very low. This variation is not only due to the educational level status but also the socioeconomic status of the family members as reported by Gage (1995).

Mass media like TV, Radio and Periodicals play a vital role to raise the awareness in this field and there was no significant difference between the two groups, which were studied here in upper middle group, having the value of $53.33 \%$ and in low-economic-group the value of $55.45 \%$ (Table 3 ). The role of mass media to raise awareness level in adolescent was supported by Watsa (1994). In contrast, teachers play a vital role for such awareness in upper-middle group but friends play key role in low-socio-economic-group (Table-3). This is also due to variation in socio-economic status of the family as in upper-middle group, the parents restriction for adolescent girls is very high that resist their free discussion with their friends, which is not applicable for low-economic group as per the observation of Beekle and McCabe (2006).

Some questions were framed to know the attitude of the adolescent girls of both groups about the futures national problems that may be developed due to uncontrolled family size. It has been indicated that the levels of unawareness

Table 1: Education level of father and mother.

\begin{tabular}{|c|c|c|c|c|c|c|c|c|}
\hline \multirow[t]{2}{*}{$\overline{\text { Group }}$} & \multicolumn{2}{|c|}{$\begin{array}{c}\text { Parent } \\
\text { (Any one/Both) } \\
\text { postgraduate }\end{array}$} & \multicolumn{2}{|c|}{$\begin{array}{c}\text { Parents } \\
\text { (Any one/Both) } \\
\text { graduate }\end{array}$} & \multicolumn{2}{|c|}{$\begin{array}{c}\text { Madhyamik } \\
\text { complete } \\
\text { (Anyone /Both) }\end{array}$} & \multicolumn{2}{|c|}{$\begin{array}{c}\text { Not completed } \\
\text { Madhyamik } \\
\text { (Both/Anyone) }\end{array}$} \\
\hline & Number & $\%$ & Number & $\%$ & Number & $\%$ & Number & $\%$ \\
\hline Group A $(\mathrm{N}=1140)$ & 300 & $26.31 *$ & 520 & $45.61 *$ & 185 & $16.23 *$ & 135 & $11.84 *$ \\
\hline Group B $(\mathrm{N}=2000)$ & 446 & $4.25 *$ & 85 & $22.30 *$ & 482 & $24.10 *$ & 987 & $49.35^{*}$ \\
\hline
\end{tabular}

Table 2: Awareness level of different method of family planning.

\begin{tabular}{|c|c|c|c|c|c|c|c|c|c|c|}
\hline \multirow[t]{2}{*}{ Group } & \multicolumn{2}{|c|}{ Withdrawal } & \multicolumn{2}{|c|}{$\begin{array}{c}\text { Safe/ Danger } \\
\text { period }\end{array}$} & \multicolumn{2}{|c|}{$\begin{array}{l}\text { Surgical technique } \\
\text { and condom }\end{array}$} & \multicolumn{2}{|c|}{$\begin{array}{l}\text { Hormonal } \\
\quad \text { pill }\end{array}$} & \multicolumn{2}{|c|}{ Emergency } \\
\hline & Number & $\%$ & Number & $\%$ & Number & $\%$ & Number & $\%$ & Number & $\%$ \\
\hline Group A $(\mathrm{N}=1140)$ & 302 & $26.49^{*}$ & 115 & $10.09 *$ & 186 & $16.32 *$ & 489 & $42.90 *$ & 48 & $4.21 *$ \\
\hline Group B $(N=2000)$ & 509 & $25.45^{*}$ & 19 & $0.95 *$ & 1039 & $51.95 *$ & 418 & $20.90 *$ & * 15 & $0.75^{*}$ \\
\hline
\end{tabular}


Table 3: Sources of information about the method of family planning programme.

\begin{tabular}{|c|c|c|c|c|c|c|c|c|}
\hline \multirow[t]{2}{*}{ Group } & \multicolumn{2}{|c|}{ None } & \multicolumn{2}{|c|}{ Mother/elders } & \multicolumn{2}{|c|}{ Book/TV } & \multicolumn{2}{|c|}{ Teachers } \\
\hline & Number & $\%$ & Number & $\%$ & Number & $\%$ & Number & $\%$ \\
\hline Group A & 61 & $5.35^{*}$ & 286 & $25.09 *$ & 608 & $53.33^{*}$ & 185 & $16.23^{*}$ \\
\hline Group B $(\mathrm{N}=2000)$ & 331 & $16.55^{*}$ & 485 & $24.25^{*}$ & 1109 & $55.45 *$ & 75 & $3.75 *$ \\
\hline
\end{tabular}

Chi-square $\left(\chi^{2}\right)=24.4858 \quad \mathrm{df}=(\mathrm{k}-1) \quad \mathrm{P}<0.001 *$

Table 4: Awareness of facts about over population and attitude of adolescent towards population problem.

\begin{tabular}{|c|c|c|c|c|c|c|c|c|}
\hline \multirow[t]{3}{*}{ Issue } & \multicolumn{4}{|c|}{ Awareness } & \multicolumn{4}{|c|}{ Unawareness } \\
\hline & \multicolumn{2}{|c|}{ Group A } & \multicolumn{2}{|c|}{ Group B } & \multicolumn{2}{|c|}{ Group A } & \multicolumn{2}{|c|}{ Group B } \\
\hline & Number & $\%$ & Number & $\%$ & Number & $\%$ & Number & $\%$ \\
\hline Need to control over population. & 918 & 80.5 & 1316 & 65.8 & 222 & $19.5^{*}$ & 684 & $34.2 *$ \\
\hline $\begin{array}{l}\text { Negative impact of over population } \\
\text { on our happiness. }\end{array}$ & 805 & 70.6 & 1376 & 68.8 & 335 & $29.4 *$ & 624 & $31.2 *$ \\
\hline $\begin{array}{l}\text { Responsibility to control population } \\
\text { problem. }\end{array}$ & 1055 & 92.5 & 1452 & 72.6 & 85 & $7.5^{*}$ & 548 & $27.4 *$ \\
\hline $\begin{array}{l}\text { Impact on resources due to over } \\
\text { population and it must be controlled. }\end{array}$ & 986 & 86.5 & 1510 & 75.5 & 154 & $13.5^{*}$ & 490 & $24.5 *$ \\
\hline High fertility rate must be controlled. & 1011 & 88.7 & 1458 & 72.9 & 129 & $11.3^{*}$ & 542 & $27.1 *$ \\
\hline $\begin{array}{l}\text { Coming generation will face problem } \\
\text { instead of reduction in population. }\end{array}$ & 702 & 61.8 & 1004 & 50.2 & 438 & $38.2^{*}$ & 996 & $49.8 *$ \\
\hline $\begin{array}{l}\text { Not in favour to increase the nation } \\
\text { population. }\end{array}$ & 891 & 78.2 & 1394 & 69.7 & 249 & $21.8^{*}$ & 606 & $30.3 *$ \\
\hline
\end{tabular}

about the negative impact of over population on future happiness, natural resource management etc, are significantly differ from between these two groups and it is very low in low-economic group (Table 4). The socio-economic factors play a key role in this purpose that has been supported by Aggarwal et al. (2005).

Lack of adequate knowledge in family planning methods and the poor attitude and practices about negative side of over population in adolescent girls may result in early pregnancy and sexual disharmony as observed by Gupta (1994). The awareness programme should be included in formal education system especially in the school curricula so that adolescent girls can acquire correct knowledge from reliable and social accepted sources rather than from so called magazine, pornography etc.

\section{REFERENCES}

Aggarwal H, Vaid S, Vaid N 2005. Comparison of the level of awareness of family planning measure in the urban and urban-slum women. Anthropol, 7: 35-40.

Balakrishna S 1971. Family planning knowledge attitude and practice. National Institute of Commun Develop, Survey Report Hyderabad, p. 139.

Beekle AT, Mc Cabe C 2006. Awareness and determinants of family planning practice in Jimma, Ethiopia. Inter Nursing Review, 53: 269-276.
Diaz J, Diaz M 1993. Quality of care in family planning on Latin America. Advance Contracep, 9: 117-128.

Gage AJ 1995.Women socio-economic position and contraceptive behavior in Togo. Study Family Plan, 26: 264-277.

Gandhi AB 1999. Reproductive health of adolescent girl. $J$ of Obstet and Gynecol of India, 49:132-135.

Gupta M 1994. Sexuality in the Indian subcontinent. Sex and Marital Therap, 9: 57-69.

Gupta S, Sinha A 2006. Awareness about reproduction and adolescent changes among school girls of different socioeconomic status. The J of Obstet and Gynecol of India, 56: 324-328.

Hate CA 1970. Raising the Age at Marriage. Indian J of Social Work, 302.

Rajamanickam M 1998. Family Planning and Birth Control Attitude Scale (FPBCAS). Institute of Community Guidance and Research, Report. Chennai.

Saipre KE 1996. Contribution to obstetrics and gynecology. Pearson Professional. Singapore.47:2.

Shah NA, Nisar N, Qudri MH 2008. Awareness and pattern of utilizing family planning services among women attending urban health care center Azizabad Sukkur. Pak J of Med Sci, 24: 550-555.

Singh K 1976. National Population Policy. Ministry of Health and Family Planning, New Delhi.

Verma A, Achhpal B 1980. Towards Better Families. An Integrated Approach to Family Life Education. A Monograph by Family Planning Association of India (MFPAI). Baroda. p.1-35.

Wasta MC 1994. Young Sexuality. Mumbai (SECERT). Family Planning Association of India.

WHO 1970. Technical report. Serial No. 483. Geneva: Switzerland. 